\title{
Striking a chord
}

\section{Landscapes: when perturbed by climatic and tectonic changes, landscapes resonate with a range of frequencies.}

\section{Philip Allen}

$\mathrm{H}$ ow is the physical form of a landscape linked to the wide array of processes that shape it? Such processes range from the patter of tiny raindrops, and the shuffling of beetles and rodents on hill slopes, to major slope failures that generate colossal debris flows, and cratering caused by the impacts of meteorites. To some, the issue is encapsulated in the conflicting imagery of 'catastrophism' and 'continuity' (or 'uniformitarianism') - two opposing views in a debate that is almost as old as the discipline of geology itself.

To take an analogy from the world of art, the uniformitarian or continuity school of thought sees the geological and geomorphological canvas as being made up of the gradual accumulation of minute brush strokes - much like that produced when a pointillist, such as Georges Seurat, adds the unremarkable dots to his picture. Landscapes viewed in this way are orderly, predictable, reassuring, perhaps even benevolent.

But another kind of canvas, such as a van Gogh, is characterized by wild brush strokes of vivid colour, and is restless, unpredictable and disconcerting. This catastrophic view sees landscapes, and indeed Earth history, as being shaped predominantly by exceptional events. If this is the case, present-day processes cannot fully explain the physical nature of the world around us: most largescale events have not been experienced by humans, and can only be surmised from geological studies of 'deep time'.

The irony of the catastrophism versus continuity debate is that no real dividing line exists between the 'ordinary' and the 'exceptional'. For example, plots of data from thousands of landslides that occurred during the past 60 years in the Southern Alps of New Zealand describe a beautiful power law, supporting the view that landscape change follows a continuum in magnitude and frequency. This implies that it is impossible to separate the exceptional from the ordinary, and invites us to realign our thinking and develop a new vocabulary when investigating the processes that shape landscapes.

We can consider landscapes as the changing geometrical form of a critical interface between two interacting systems: an internal system driven essentially by tectonic fluxes of rock, and an external system dominated by the effects of climate. The challenging

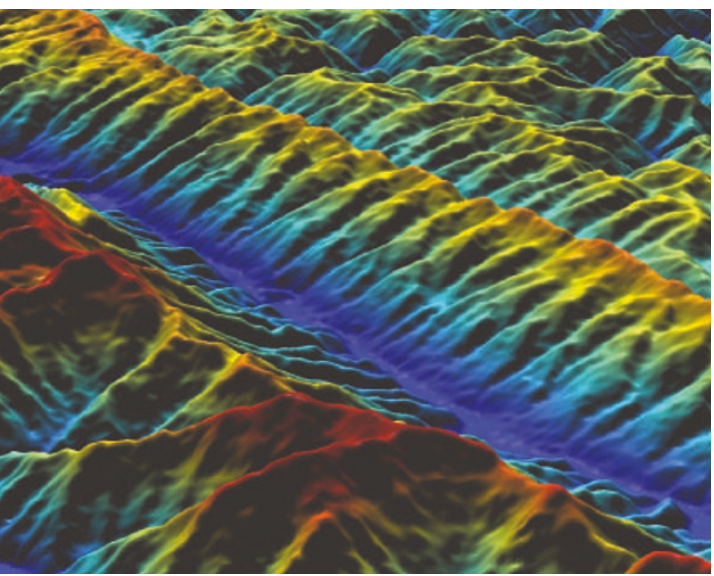

Making waves: a digital reconstruction of a landscape from Kentucky, United States, reveals regular transverse catchments.

feature of these two interacting systems is that they each operate at a range of temporal and spatial scales. We can think of landscapes as being perturbed by variations in both internal and external mechanisms. The results of these perturbations might be seen as changes in the morphometric properties of the critical interface or as changes in the mass fluxes of rock, particulate sediment or solutes through and over it.

In the past, tectonic movements were somewhat statically viewed as effectively instantaneous events causing uplift of the land surface, and upon which geomorphic agents worked over eons of time. It is now clear that in regions of active tectonics, the rates at which tectonic and geomorphic processes operate are similar. Consequently, the possibilities for complex coupling of the two processes are enormous.

An exciting avenue of research at present is evaluating the response of landscapes to perturbations, such as changes in tectonic and climatic conditions. For example, the landscapes of the Basin and Range province in western United States are continually adjusting to the tectonic deformation of the underlying crust. This tectonic deformation is essentially caused by the growth of faults to accommodate extension of the crust, and is responsible for uplifted ranges with steep transverse rivers that feed cone-shaped 'fans' of sediment in adjoining basins. Although such a system appears, at first, to be relatively simple, its operation is determined by the timescales over which several interacting geomorphic subsystems respond to perturbations. Rather than resonating like a single hand-held bell, landscapes are polychromatic, resonating with different frequencies when perturbed, like the strings of a guitar that generate chords when struck at different fret positions.

So instead of being seen as continuous or catastrophic, I propose that landscapes be considered in terms of their response times to various perturbations, such as the lateral growth of an active fault, or the change in the rate at which a major fault slips due to the accumulated effect of earthquakes. Landscapes can be viewed as 'buffered' when their response to rapidly repeating perturbations is slow, but 'reactive' when their response is rapid compared to the frequency of the disturbance. Landscapes can also be termed 'steady' when their response time is smaller than the interval between a repeated perturbation, or less than the time passed since a change in the prevailing tectonic or climatic conditions, but 'transient' when the reverse is true.

One of the goals of the burgeoning field of research working on Earth surface processes must be to improve measurements of the rates of tectonic, sedimentologic and geomorphologic processes using the rapidly improving tools that are available. Such tools include the digital description of landscapes; the dating of geomorphic surfaces and events; the elucidation of the spatial patterns of denudation at different timescales; and the use of numerical methods in coupled geomorphic tectonic-climate modelling of integrated systems routing sediment from erosional mountain slopes to depositional basins. With these new data, we will be better able to establish what meaningful information about the forces shaping landscapes can be interpreted from its geometrical form, mass fluxes and sedimentary deposits. Put simply, we may learn how to read the epic poem of Earth history that is written in sediments and landscapes.

Philip Allen is in the Department of Earth Sciences, ETH-Zentrum, CH-8092 Zurich, Switzerland.

\section{FURTHER READING}

Summerfield, M. A. (ed.) Geomorphology and Global Tectonics (Wiley, 2000)

Allen, P. A. \& Allen, J. R. Basin Analysis: Principles and Applications 2nd edn Ch. 7, 221-265 (Blackwell, 2005).

This essay is based on the William Smith Lecture given at the Geological Society of London's conference 'Earth's Dynamic Surface: Catastrophe and Continuity in Landscape Evolution', 4-5 October 2004 